\title{
Montelukast protects against nasal lysine-aspirin challenge in patients with aspirin-induced asthma
}

\author{
D.K.C. Lee, K. Haggart, F.M. Robb, B.J. Lipworth
}

Montelukast protects against nasal lysine-aspirin challenge in patients with aspirininduced asthma. D.K.C. Lee, K. Haggart, F.M. Robb, B.J. Lipworth. C ERS Journals Ltd 2004.

ABSTRACT: Aspirin-induced asthma (AIA) is associated with increased production of

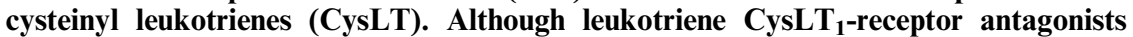
improve lower airway outcomes in AIA, their effects and dose-response in the upper airway is less well documented.

The present study evaluated the dose-response for montelukast (ML) against nasal lysine-aspirin challenge in patients with AIA.

A total of 12 patients with a clear-cut history of AIA were randomised in double-blind cross-over fashion to receive single doses of ML $10 \mathrm{mg}$, ML $40 \mathrm{mg}$, or placebo (PL), with nasal lysine-aspirin challenge performed $12 \mathrm{~h}$ after dosing. Measurements of peak nasal inspiratory flow (PNIF), nasal blockage visual analogue scale (VAS) and forced expiratory volume in one second (FEV1) were made over 120 min after nasal lysineaspirin challenge.

Prechallenge values for mean \pm SEM PNIF $\left(\mathrm{L} \cdot \mathrm{min}^{-1}\right)$ were not significantly different comparing all groups: ML $10 \mathrm{mg}$ (132 \pm 10$)$, ML $40 \mathrm{mg}(125 \pm 12)$ and PL (132 \pm 11$)$. There was no significant difference comparing the maximum \% PNIF fall from baseline between screening (46 \pm 6 ) and PL (45 \pm 6$)$. The maximum $\%$ PNIF fall from baseline was significantly greater with PL (45 \pm 6$)$ compared to either ML $10 \mathrm{mg}(34 \pm 6)$ or ML $40 \mathrm{mg}$ $(32 \pm 5)$. There was also a significantly greater mean \% PNIF response over 120 min after lysine-aspirin challenge for PL $(26 \pm 7)$ compared to either ML $10 \mathrm{mg}(14 \pm 6)$ or ML $40 \mathrm{mg}(17 \pm 6)$. There were no significant differences for the maximum or mean $\%$ PNIF fall from baseline comparing ML $10 \mathrm{mg}$ and ML $40 \mathrm{mg}$. A significant increase in nasal blockage VAS score was observed between baseline and $60 \mathrm{~min}$ or $120 \mathrm{~min}$ with PL but not with ML $10 \mathrm{mg}$ or ML $40 \mathrm{mg}$. There were no significant differences for either the maximum or mean \% FEV1 over 120 min as change from baseline comparing all groups.

A single $10 \mathrm{mg}$ dose of montelukast partially protected against the local effects of nasal lysine-aspirin challenge, with no further benefit at $\mathbf{4 0} \mathrm{mg}$. Nasal lysine-aspirin challenge appeared to be a reproducible and safe method in assessing patients with aspirin-induced asthma.

Eur Respir J 2004; 24: 226-230.
Asthma and Allergy Research Group, Ninewells Hospital and Medical School, University of Dundee, Dundee, Scotland, UK.

Correspondence: B.J. Lipworth

Asthma and Allergy Research Group Ninewells Hospital and Medical School

University of Dundee

Dundee DD1 9SY

Scotland

UK

Fax: 441382644972

E-mail: b.j.lipworth@dundee.ac.uk

Keywords: Aspirin-induced asthma cysteinyl leukotrienes montelukast

nasal blockage visual analogue scale nasal-lysine aspirin challenge peak nasal inspiratory flow

Received: September 42003 Accepted after revision: March 92004

This study was supported by a University of Dundee departmental grant from the Anonymous Trust and received no support from the pharmaceutical industry.
Aspirin-induced asthma (AIA) is a syndrome precipitated by ingestion of aspirin and nonsteroidal anti-inflammatory drugs [1]. AIA is characterised by the presence of chronic rhinosinusitis, nasal polyposis, and asthma, associated with eosinophilic mucosal inflammation [2] and overproduction of cysteinyl leukotrienes [1,3-8]. The mechanism of AIA is thought to be due to an accelerated depletion of prostaglandin $E_{2}$ by aspirin, the former already downregulated because of cyclooxygenase COX-2 functional deficiency [1]. AIA may affect up to $10 \%$ of adults with asthma [9] and is frequently preceded by chronic rhinosinusitis and nasal polyposis $[1,10]$.

Nasal lysine-aspirin challenge had been proposed as a safe test to diagnose AIA, and is without risk of bronchospasm sometimes associated with bronchial aspirin challenge [10]. Moreover, nasal provocation with lysine-aspirin may be safer and preferable compared to oral aspirin challenge, the latter being potentially hazardous, especially in patients with a history of aspirin-induced anaphylaxis. Leukotriene receptor antagonists (LTRA), which competitively block CysLT ${ }_{1}^{-}$ receptors [11-13], have been shown to improve lower airway parameters in patients with AIA [14-16]. However, the effect of LTRA in the upper airway are poorly characterised in AIA, particularly with respect to nasal lysine-aspirin challenge. It also remains unclear whether patients with AIA may benefit from a higher than conventional dose of LTRA, in view of the increased production of cysteinyl leukotrienes. Therefore, an evaluation of the dose-response for montelukast (ML) in patients with AIA, against nasal lysine-aspirin challenge was undertaken.

\section{Methods}

\section{Patients}

Selected patients were required to exhibit a clear-cut history of AIA, with the presence of chronic rhinosinusitis, nasal polyposis, asthma, and aspirin sensitivity, in addition to a positive response to nasal lysine-aspirin challenge. Patients had evidence of chronic sinus inflammation on computed tomography scanning and the presence of grade 1-2 nasal 
polyps were determined via nasal endoscopy. Patients with occlusive grade 3 nasal polyps were excluded, as significant nasal obstruction would have prevented proper measurement of their peak nasal inspiratory flow (PNIF). In order to confirm sensitivity to aspirin, patients were required at screening to demonstrate a positive response to nasal lysine-aspirin challenge, as defined by a maximal fall in PNIF of $\geqslant 25 \%$ from baseline over a 120-min period after challenge. Patients stopped any concomitant LTRA during a 1-week washout period prior to the initial screening challenge, and for the duration of the study. Patients were also required to withhold any short-acting $\beta_{2}$-agonists and long-acting $\beta_{2}$-agonists for $\geqslant 6 \mathrm{~h}$ and $48 \mathrm{~h}$ respectively, prior to each study visit. All patients gave informed consent and the study was approved by the Tayside Committee on Medical Research Ethics.

\section{Study design}

The study was conducted in a randomised, double-blind, placebo (PL)-controlled, cross-over fashion. Patients were randomised to receive a single dose of ML $10 \mathrm{mg}$ (Singulair (R, Merck Sharp \& Dohme Ltd, Hoddesdon, UK), ML $40 \mathrm{mg}$, or PL. All tablets were encapsulated and were identical in external physical appearance. Patients took the study capsules at 22:00 $\mathrm{h}$ and attended the department the next morning at 10:00 h. There was a 1-week washout period between each study visit.

\section{Measurements}

Nasal endoscopy. Subjects with a significant degree of nasal septal deviation of $>50 \%$ and occlusive grade 3 nasal polyposis were excluded by nasal endoscopy using a rigid $30^{\circ}$ Hopkins $\mathbb{R}$ Telescope (Karl Storz Endoscopy Ltd, Slough, UK).

Peak nasal expiratory flow. All patients received appropriate instructions and were required to demonstrate good technique in recording their PNIF using the In-Check $\mathbb{R}$ PNIF meter (Clement Clarke International Ltd, Harlow, UK) at the initial screening visit. The technique was then further reassessed and reinforced, prior to each nasal challenge, at each study visit.

Spirometry. Spirometry was performed according to the American Thoracic Society criteria [17] using a Vitalograph $\mathbb{R}$ compact spirometer (Vitalograph Ltd, Buckingham, UK) with a computer-assisted pneumotachograph head and pressure transducer. The spirometer was calibrated daily with a

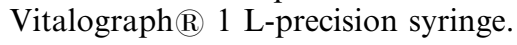

Nasal lysine-aspirin challenge. Nasal lysine-aspirin challenge was performed as previously described [18]. In brief, patients

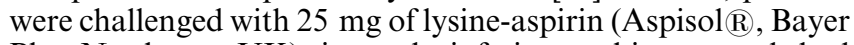
Plc, Newbury, UK) in each inferior turbinate, and had measurements of PNIF and spirometry at 10-min intervals, over a 120-min period after challenge. Patients also had recording of nasal blockage symptoms prior to challenge, and at $60 \mathrm{~min}$ and $120 \mathrm{~min}$ after challenge, using a visual analogue scale (VAS) ranging from 0 (no symptoms) to 10 (very severe symptoms).

\section{Statistical analysis}

The primary outcome variable was calculated as the maximum \% PNIF fall from baseline over $120 \mathrm{~min}$ after nasal lysine-aspirin challenge. The power of the study was
$80 \%$ with an $\alpha$-error set at 0.05 (2-tailed) in order to detect a $25 \%$ difference in the maximum response between ML and PL, with a sample size of 12 completed patients in a crossover design. Secondary outcomes included the average response over $120 \mathrm{~min}$, as well as the nasal blockage VAS score at $60 \mathrm{~min}$ and $120 \mathrm{~min}$ after challenge. Analysis of variance was used to compare the response to randomised treatments followed by Bonferroni-corrected multiple-range testing set at $95 \%$ CI. In addition, data were analysed according to sequence of randomised treatments in order to evaluate any potential carry-over effects.

\section{Results}

\section{Patients}

A total of 12 patients (five male and seven female) with a mean \pm SEM age of $48 \pm 3$ yrs were enrolled and all completed the study. All patients were receiving therapy for AIA including inhaled corticosteroids (ICS) (beclomethasone dipropionate: $n=3$; budesonide: $n=2$; and fluticasone propionate: $n=3$ ), intranasal corticosteroids (fluticasone propionate: $n=12$ ), LTRA $(n=6)$, long-acting $\beta_{2}$-agonists $(n=1)$ and short-acting $\beta_{2}$-agonists $(n=12)$. The daily dose of ICS $(1,225 \pm 358 \mu \mathrm{g})$ and intranasal corticosteroids $(600 \pm 60 \mu \mathrm{g})$ remained unchanged throughout the study.

\section{Lysine-aspirin challenge reproducibility}

In order to determine the consistency of the nasal response to lysine-aspirin, separate challenges were performed at screening and following PL (fig. 1). There was no significant difference comparing the maximum \% PNIF fall from baseline between screening ( $46 \pm 6)$ and PL $(45 \pm 6)$. The coefficient of variation for the reproducibility of the lysine-aspirin challenge was $4.2 \%$.

\section{Peak nasal expiratory flow}

Prechallenge PNIF $\left(\mathrm{L} \cdot \mathrm{min}^{-1}\right)$ was not significantly different comparing all groups: ML $10 \mathrm{mg}(132 \pm 10$, mean \pm SEM), ML

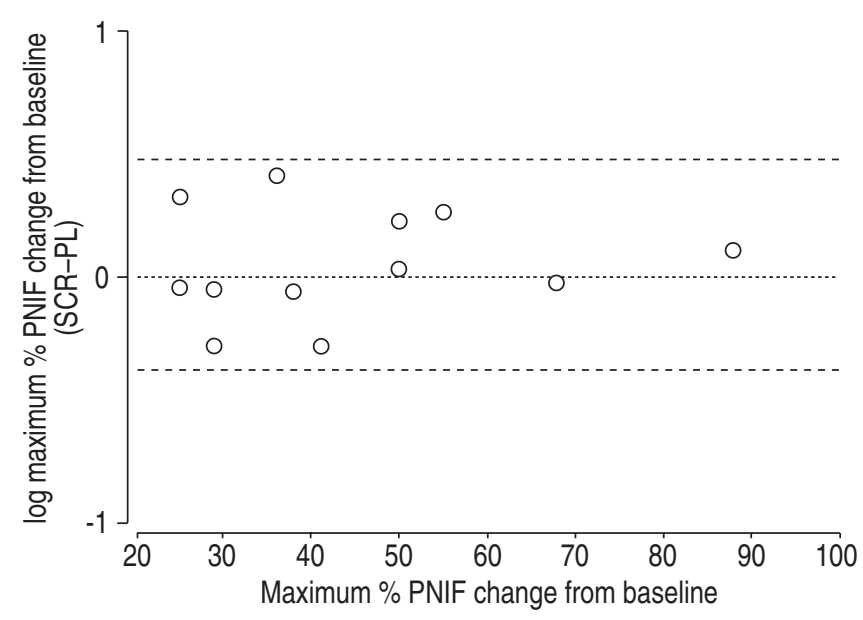

Fig. 1.-Bland and Altman plot for the maximum percentage (\%) peak nasal inspiratory flow (PNIF) change from prechallenge baseline. The middle line indicates the point of no difference between screening (SCR) and placebo (PL), and the dashed lines indicate the $95 \% \mathrm{CI}$. 
$40 \mathrm{mg}(125 \pm 12)$ and PL (132 \pm 11$)$. The maximum \% PNIF fall from baseline (fig. 2) was significantly greater $(\mathrm{p}<0.05)$ with PL (45 \pm 6$)$ compared to either ML $10 \mathrm{mg}(34 \pm 6$; mean difference: 12 (95\% CI: 4-21)), or ML $40 \mathrm{mg}$ (32 \pm 5 ; mean difference: 13 (95\% CI: 2-24)). The average \% PNIF fall from baseline over $120 \mathrm{~min}$ (fig. 3) was also significantly greater $(\mathrm{p}<0.05)$ with PL $(26 \pm 7)$ compared to either ML $10 \mathrm{mg}$

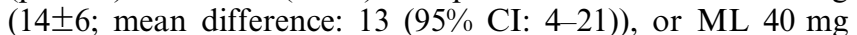
(17 \pm 6 ; mean difference: 10 (95\% CI: $1-19)$ ). There were no significant differences for both the maximum or average $\%$ PNIF fall from baseline over $120 \mathrm{~min}$, comparing ML $10 \mathrm{mg}$ and $\mathrm{ML} 40 \mathrm{mg}$. Individual data showed no discernible pattern of any dose-response effect between ML $10 \mathrm{mg}$ and ML $40 \mathrm{mg}$ (fig. 2). Data for absolute PNIF values over $120 \mathrm{~min}$ after nasal lysine-aspirin challenge are also shown (fig. 3). There were no significant differences for any outcome variable when data were analysed according to the sequence in which the randomised treatments were given, thus indicating the absence of any carry-over effect.

\section{Nasal blockage visual analogue scale score}

In the PL group, nasal blockage VAS score (fig. 4) compared to baseline $(1.3 \pm 0.5)$ was significantly greater $(\mathrm{p}<0.05)$ at both $60 \mathrm{~min}(2.7 \pm 0.8$; mean difference: $1.3(95 \%$ CI: $0.2-2.4))$ and $120 \mathrm{~min}(3.1 \pm 0.9$; mean difference: $1.8(95 \%$ CI: 0.4-3.1)). There were no significant differences comparing
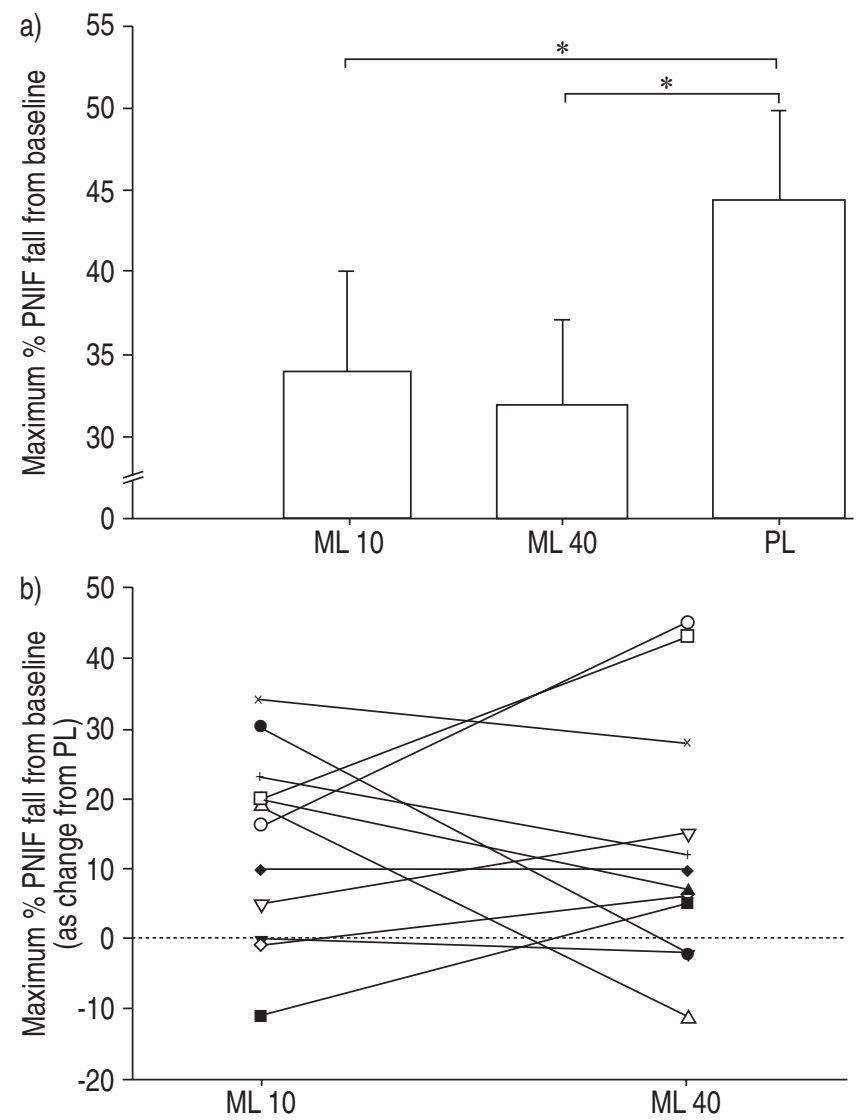

Fig. 2.-a) Mean \pm SEM maximum percentage (\%) peak nasal inspiratory flow (PNIF) fall from prechallenge baseline for montelukast $10 \mathrm{mg}$ (ML 10), montelukast $40 \mathrm{mg}$ (ML 40) and placebo (PL); b) Individual data for maximum $\%$ PNIF fall from prechallenge baseline, as change from PL, showing ML 10 and ML 40 values coupled for each individual. $*$ : $\mathrm{p}<0.05$
$60 \mathrm{~min}$ or $120 \mathrm{~min}$ and baseline in both the ML $10 \mathrm{mg}$ and ML $40 \mathrm{mg}$ group. The change from baseline was significantly
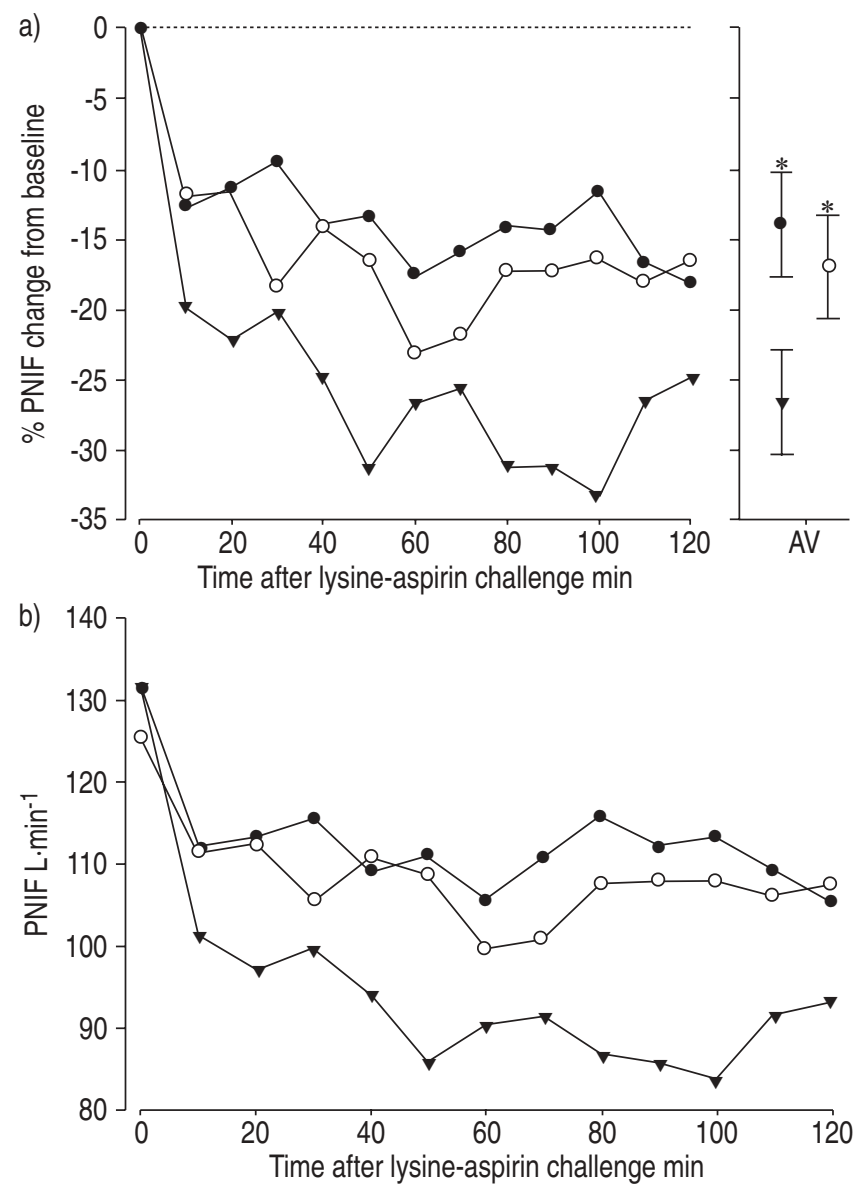

Fig. 3. - a) Time-response profile of percentage (\%) peak nasal inspiratory flow (PNIF) change from prechallenge baseline after nasal lysine-aspirin challenge, and mean \pm SEM $\%$ PNIF fall from prechallenge baseline over $120 \mathrm{~min}(\mathrm{AV})$; b) time-response profile of absolute PNIF values after nasal lysine-aspirin challenge over $120 \mathrm{~min}$. *: $\mathrm{p}<0.05$ between placebo $(\boldsymbol{\nabla})$ and montelukast $10 \mathrm{mg}(\boldsymbol{\bullet})$ or montelukast $40 \mathrm{mg}(\bigcirc)$.

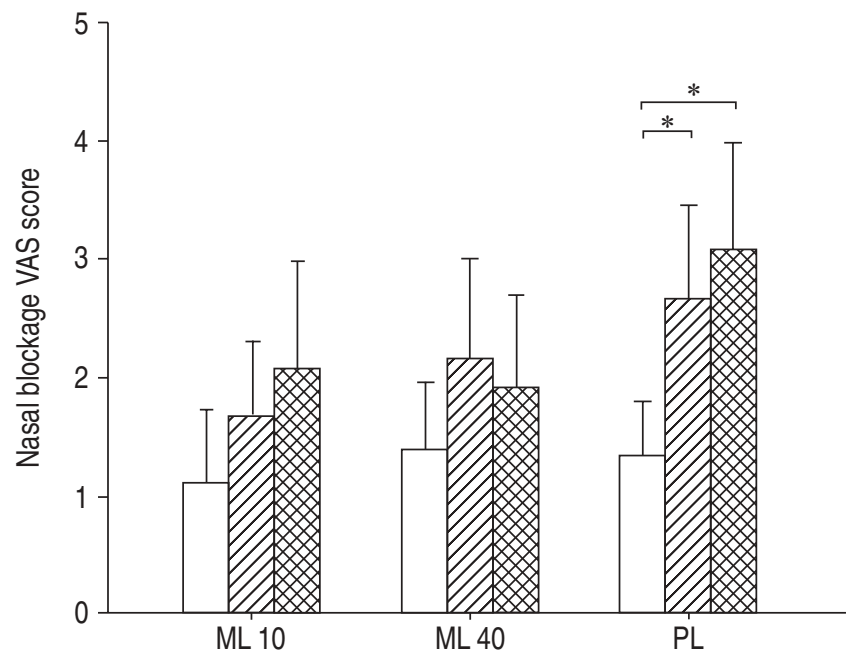

Fig. 4. - Mean \pm SEM nasal blockage visual analogue scale score at prechallenge baseline $(\square)$, and at $60(\mathbb{Z})$ and $120(\mathbf{D})$ min after nasal lysine-aspirin challenge. ML 10: montelukast $10 \mathrm{mg}$; ML 40: montelukast $40 \mathrm{mg}$; PL: placebo. 


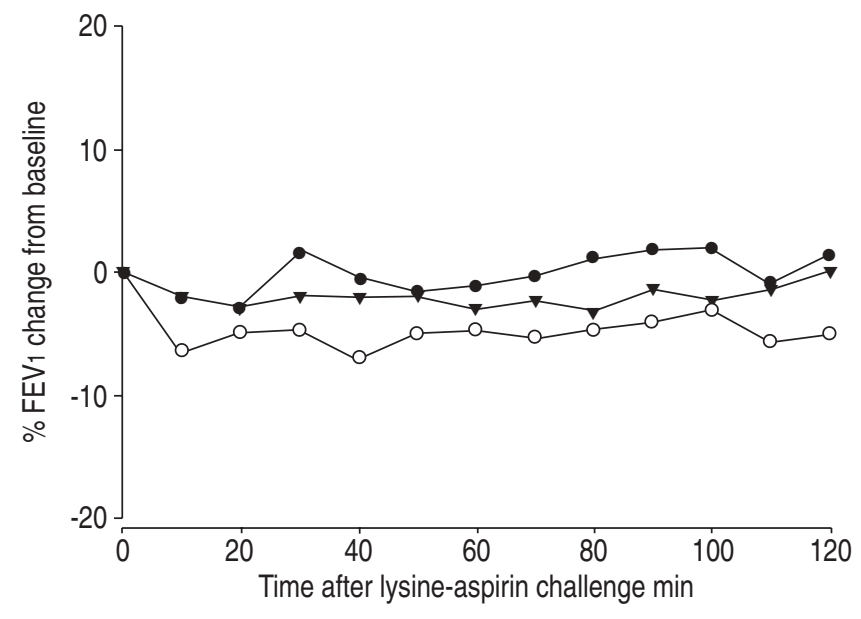

Fig. 5.-Time-response profile of percentage (\%) FEV1 change from prechallenge baseline after nasal lysine-aspirin challenge. $\boldsymbol{\nabla}$ : placebo; : montelukast $10 \mathrm{mg} ; \bigcirc$ : montelukast $40 \mathrm{mg}$.

greater $(\mathrm{p}<0.05)$ at $120 \mathrm{~min}$ for PL $(1.8 \pm 0.6)$ compared to ML $40 \mathrm{mg}(0.5 \pm 0.4$; mean difference: 1.2 (95\% CI: $0.1-2.4)$ ).

\section{Forced expiratory volume in one second}

Prechallenge FEV1 was not significantly different comparing all groups: ML $10 \mathrm{mg}(2.71 \pm 0.24 \mathrm{~L}), \quad \mathrm{ML} 40 \mathrm{mg}$ $(2.82 \pm 0.28 \mathrm{~L})$ and PL $(2.73 \pm 0.27 \mathrm{~L})$. There were no significant differences for either the maximum or average $\%$ FEV1 over $120 \mathrm{~min}$ as change from baseline comparing all groups (fig. 5).

\section{Discussion}

The present study results show that ML partially attenuated the local response to nasal lysine-aspirin challenge in patients with AIA. Moreover, the presented data have also demonstrated that nasal lysine-aspirin challenge is both reproducible and safe when used to assess patients with AIA. ML protected against the effects of lysine-aspirin by attenuating lysineaspirin induced nasal obstruction, measured objectively with PNIF and subjectively using nasal blockage VAS score.

The current results would suggest a plateau in the doseresponse for ML at $10 \mathrm{mg}$, which is the conventional recommended dose [19]. This is perhaps surprising given the overproduction of cysteinyl leukotrienes in AIA [1, 3-8]. The effects of ML were observed as add-on therapy to intranasal corticosteroids, the latter being unchanged throughout the study. This was expected as corticosteroids have been shown to have little effect on the biosynthesis of cysteinyl leukotrienes [20].

FEV1 remained virtually unchanged throughout the lysineaspirin challenge in the present study, suggesting that lysineaspirin-induced nasal obstruction in the upper airway does not influence the lower airway to trigger bronchoconstriction. This is reassuring given that $25 \%$ of patients in the current study have previously reported severe systemic reactions following ingestion of aspirin leading to angio-oedema and severe bronchospasm, requiring hospitalisation. The remaining patients had a history of severe bronchospasm following ingestion of aspirin but no angio-oedema.

A maximal fall in PNIF of $\geqslant 25 \%$ from baseline was chosen in order to indicate a positive response to nasal lysine-aspirin, in keeping with previous data showing similar cut-off value using acoustic rhinometry [18]. PNIF has been shown to be a more sensitive measurement compared to either acoustic rhinometry or rhinomanometry, when used with nasal histamine challenge [21]. In addition, PNIF has also been found to have a low degree of intra-individual variability of $8 \%$ for repeated measurements over the short-term in patients with allergic rhinitis [22].

The presented data would suggest a potential role for ML in attenuating the nasal response induced by aspirin in patients with AIA, although prospective placebo-controlled randomised chronic dosing studies are required to properly evaluate objective and subjective responses. In an open audit study, ML was found to produce variable responses in patients with nasal polyposis, with no difference in subjective response between aspirin tolerant and intolerant patients [23]. However, as ML has been shown to benefit aspirin intolerant patients with asthma, it would seem rational that ML may also benefit patients with concomitant chronic rhinosinusitis and nasal polyposis. It is conceivable that the present study may have missed a difference in the nasal response between the doses of $\mathrm{ML}$ as there is sometimes a prolonged response after aspirin challenge, which is attributable to the influx of inflammatory cells. Moreover, although ML protected against the effects of nasal lysine-aspirin in the current study, it did not completely obliterate the response. This would be in keeping with a previous observation showing ML to be only partially effective in altering the response to oral aspirin challenge [24]. As there are multiple mediators involved in the pathogenesis of AIA, the partial protection observed with ML would indicate a lack of antagonism of other receptors, such as prostaglandin $\mathrm{PGD}_{2}$-receptors and histamine $\mathrm{H}_{1}$-receptors.

In conclusion, montelukast at a clinically recommended dose of $10 \mathrm{mg}$ partially protected against the local effects of nasal lysine-aspirin challenge, which in turn appears to be a reproducible and safe method in assessing patients with aspirin-induced asthma. There was no benefit attained by increasing the dose of montelukast to $40 \mathrm{mg}$.

\section{References}

1. Szczeklik A, Stevenson DD. Aspirin-induced asthma: Advances in pathogenesis, diagnosis, and management. J Allergy Clin Immunol 2003; 111: 913-921.

2. Nasser SM, Pfister R, Christie PE, et al. Inflammatory cell populations in bronchial biopsies from aspirin-sensitive asthmatic subjects. Am J Respir Crit Care Med 1996; 153: 90-96.

3. Kawagishi $\mathrm{Y}$, Mita H, Taniguchi M, et al. Leukotriene C4 synthase promoter polymorphism in Japanese patients with aspirin-induced asthma. J Allergy Clin Immunol 2002; 109: 936-942.

4. Christie PE, Tagari P, Ford-Hutchinson AW, et al. Urinary leukotriene E4 concentrations increase after aspirin challenge in aspirin-sensitive asthmatic subjects. Am Rev Respir Dis 1991; 143: 1025-1029.

5. Kumlin M, Dahlen B, Bjorck T, Zetterstrom O, Granstrom E, Dahlen SE. Urinary excretion of leukotriene E4 and 11dehydro-thromboxane $\mathrm{B} 2$ in response to bronchial provocations with allergen, aspirin, leukotriene D4, and histamine in asthmatics. Am Rev Respir Dis 1992; 146: 96-103.

6. Israel E, Fischer AR, Rosenberg MA, et al. The pivotal role of 5-lipoxygenase products in the reaction of aspirin-sensitive asthmatics to aspirin. Am Rev Respir Dis 1993; 148: 1447-1451.

7. Oosaki R, Mizushima Y, Mita H, Shida T, Akiyama K, Kobayashi M. Urinary leukotriene E4 and 11dehydrothromboxane B2 in patients with aspirin-sensitive asthma. Allergy 1997; 52: 470-473.

8. Yoshida S, Sakamoto H, Ishizaki Y, et al. Efficacy of 
leukotriene receptor antagonist in bronchial hyperresponsiveness and hypersensitivity to analgesic in aspirinintolerant asthma. Clin Exp Allergy 2000; 30: 64-70.

9. Szczeklik A. Mechanism of aspirin-induced asthma. Allergy 1997; 52: 613-619.

10. Milewski M, Mastalerz L, Nizankowska E, Szczeklik A. Nasal provocation test with lysine-aspirin for diagnosis of aspirin-sensitive asthma. J Allergy Clin Immunol 1998; 101: 581-586.

11. De Lepeleire I, Reiss TF, Rochette F, et al. Montelukast causes prolonged, potent leukotriene D4-receptor antagonism in the airways of patients with asthma. Clin Pharmacol Ther 1997; 61: 83-92.

12. Dahlen SE. Pharmacological characterization of leukotriene receptors. Am J Respir Crit Care Med 2000; 161: S41-S45.

13. Lynch KR, O'Neill GP, Liu Q, et al. Characterization of the human cysteinyl leukotriene CysLT1 receptor. Nature 1999; 399: 789-793.

14. Drazen JM, Israel E, O'Byrne PM. Treatment of asthma with drugs modifying the leukotriene pathway. $N$ Engl J Med 1999; 340: 197-206.

15. Dahlen SE, Malmstrom K, Nizankowska E, et al. Improvement of aspirin-intolerant asthma by montelukast, a leukotriene antagonist: a randomized, double-blind, placebocontrolled trial. Am J Respir Crit Care Med 2002; 165: 914.

16. Mastalerz L, Gawlewicz-Mroczka A, Nizankowska E, Cmiel A, Szczeklik A. Protection against exercise-induced bronchoconstriction by montelukast in aspirin-sensitive and aspirin-tolerant patients with asthma. Clin Exp Allergy 2002; 32: 1360-1365.
17. American Thoracic Society. Standardization of Spirometry, 1994 Update. Am J Respir Crit Care Med 1995; 152: 1107-1136.

18. Casadevall J, Ventura PJ, Mullol J, Picado C. Intranasal challenge with aspirin in the diagnosis of aspirin intolerant asthma: evaluation of nasal response by acoustic rhinometry. Thorax 2000; 55: 921-924.

19. Altman LC, Munk Z, Seltzer J, et al. A placebo-controlled, dose-ranging study of montelukast, a cysteinyl leukotrienereceptor antagonist. Montelukast Asthma Study Group. J Allergy Clin Immunol 1998; 102: 50-56.

20. Peters-Golden M, Sampson AP. Cysteinyl leukotriene interactions with other mediators and with glucocorticosteroids during airway inflammation. J Allergy Clin Immunol 2003; 111: S37-S42.

21. Wilson AM, Sims EJ, Robb F, Cockburn W, Lipworth BJ. Peak inspiratory flow rate is more sensitive than acoustic rhinometry or rhinomanometry in detecting corticosteroid response with nasal histamine challenge. Rhinology 2003; 41: 16-20.

22. Sims EJ, Wilson AM, White PS, Gardiner Q, Lipworth BJ. Short-term repeatability and correlates of laboratory measures of nasal function in patients with seasonal allergic rhinitis. Rhinology 2002; 40: 66-68.

23. Ragab S, Parikh A, Darby YC, Scadding GK. An open audit of montelukast, a leukotriene receptor antagonist, in nasal polyposis associated with asthma. Clin Exp Allergy 2001; 31: $1385-1391$

24. Stevenson DD, Simon RA, Mathison DA, Christiansen SC. Montelukast is only partially effective in inhibiting aspirin responses in aspirin-sensitive asthmatics. Ann Allergy Asthma Immunol 2000; 85: 477-482. 